\title{
Prevalence and awareness of temporomandibular joint disorders among patients in king abdulaziz university, dental hospital
}

\begin{abstract}
Introduction: Temporomandibular disorders (TMDs) are the most prevalent orofacial pain (OFP) conditions for which patients seek treatment. In our Saudi Arabia population, limited studies regarding patients' awareness of their TMDs in relation to the presence of its symptoms were reported.
\end{abstract}

Objective: The scope of this work aims at assessing prevalence of TMD signs and symptoms in relation to patients' awareness of their occurrence.

Patients and methods: A randomized cross sectional, observational study was based on 80 patients frequenting King Abdulaziz University Dental Hospital (KAUDH). Patients answered a comprehensive questionnaire, followed by clinical and radiographic assessments.

Results: Patients' mean age was 39 years, with male to female ratio 1:5. Subjects diagnosed with TMD with at least two TMD signs and/or symptoms were $72.5 \%$. Neither age nor gender had a significant effect on TMD. Headache consisted a major symptom ( $58.6 \%$ ) followed by clicking ( $42 \%$ ) and pain $(39,6 \%$ ) while muscle tenderness was $92.8 \%$. Correlation of pain to TMD was highly significant, $28.7 \%$. Parafunctional habits were present in $33.7 \%$ of patients; however, only $81.4 \%$ were associated with TMD. Jaw movements impairment was observed only in patients suffering from TMD symptoms. Occlusal discrepancies $68.7 \%$ showed statistically significant association between loss of posterior teeth and TMD. Radiographs showed that among TMD patients; $42 \%$ had anterior condylar position, while; $30 \%$ had posterior condylar position. $32.7 \%$ of patients recognized a TMJ related problem that affected their quality of life, while $67.3 \%$ suffering from TMD were unaware of their TMJ disorder.

Conclusion: TMD was observed in our local population with two or more symptoms that negatively affect the patients' quality of life. However, awareness of the patients about their disease requires better community orientation about the significance of the disease and its prognosis.

Keywords: TMJ disorders, signs and symptoms, prevalence, awareness
Volume 8 Issue 5 - 2017

\author{
Danya A Alhussini,' Dana M Mominkhan,' \\ Farah J Alhamed,' Rawan A Saklou,' Hala M \\ Abdel Alim² \\ 'Department of Dentistry, King Abdulaziz University, Saudi \\ Arabia \\ ${ }^{2}$ Department of Oral and Maxillofacial Surgery, King Abdulaziz \\ University, Saudi Arabia
}

Correspondence: Danya A Alhussini, Department of Dentistry, King Abdulaziz University, Saudi Arabia,

Email rawlansaklou@gmail.com

Received: October 28, 2017 | Published: November 06, 2017

\section{Introduction}

Temporomandibular joint (TMJ) is one of the most complex joints in our bodies. It is made of two bony parts; glenoid fossa of the temporal bone and the head of mandibular condyle. In between, articulating disk occurs and functions as a third bone. ${ }^{1,2}$ Some of the most prevalent and debilitating pain conditions arise from the structures innervated by the trigeminal system; head, face, masticatory musculature, temporomandibular joint and associated structures. Orofacial pain (OFP) can arise from different regions and etiologies; developmental, inflammatory, traumatic, functional, or tumors. ${ }^{3}$ Temporomandibular disorders (TMDs) are the most prevalent OFP conditions for which patients seek treatment. The commonest cause of myofascial pain or OFP is TMD. It affects $5-12 \%$ of the population and the peak age is $20-40$ year. ${ }^{1,2}$ They are multi factorial disorders related to the TMJ, muscles of mastication, and the surrounding structures. The commonly associated signs and symptoms of TMDs are tenderness of the muscles and pain. ${ }^{1-6}$ TMD etiology is based on the Hybrid Theory, which stated "A combination of stress and occlusal disharmonies was responsible for the development of TMD symptoms in previously asymptomatic persons with bad occlusions". TMJ malalignment, neuromuscular imbalance in the face, nutritional theories and others have also been suggested to explain the etiology of TMD. ${ }^{7-10}$ Risk factors associated with TMD were highly related to TMD such as age, genetic factors, sex, occlusion, acute trauma, and bruxism and parafunctional habits. ${ }^{11}$ Epidemiological studies clearly demonstrate female gender predominance in TMD pain. Contradictory; other investigations showed no difference between both sexes. However; the increase in prevalence of TMD with advancing age has been recorded by Tecco $\mathrm{S}$ et al. Moreover, many symptoms occur in adolescence and may continue intermittently into middle age; however, TMD symptomatology improves with time, supporting a conservative management approach..$^{11,12}$ Several studies were undertaken to assess the prevalence, causes and management of 
TMDs. A prevalence of $53 \%$ was reported by Muhtaroğullari M et al. while Somez H et al., ${ }^{9}$ and Godoy F et al. (2007), recorded $16 \%$ to $68 \% .{ }^{13}$ In our local population, limited studies regarding the awareness and prevalence of TMD signs and symptoms of the patients about their TMDs in relation to the presence of its symptoms particularly in the Western region of Saudi Arabia, were not reported. This missing epidemiological data base concerning TMDs enthused us to study the, aggravating, relieving factors, and the relation between malocclusion, parafunctional habits and symptoms advancement, as well as patient awareness of their disease.

\section{Objectives}

The scope of this work mainly aims at assessing the prevalence of TMD signs and symptoms in relation to patients' awareness of their occurrence.

\section{Material and methods}

The present work is a randomized cross sectional, observational study, based on 80patients frequenting our dental clinics in King Abdulaziz University Dental Hospital (KAUDH).

Excluded subjects those previously diagnosed or treated as TMD patients, patients with a history of trauma or with any general systemic disease that would jeopardize sample selection.

All patients answered a well-structured comprehensive questionnaire, followed by a thorough clinical examination.

The questionnaire was based on information related to the following:

i. Demographic data.

ii. History of:

iii. Habits: Tongue thrust, bruxism, grinding, lip bite, nail bite and pencil bite.

iv. Pain (Onset, duration, periodicity, nature, site, severity, aggravating factors, relieving factors, associated factors and impact on quality of life).

v. Headache.

Examination included the following:

i. TMJ and jaw movements.

ii. Muscles of mastication palpation.

iii. Analyzing patient's occlusion.

iv. Radiographic assessment.

Subjects with TMD were defined as patients who experienced at least two of commonly associated TMD signs and symptoms: (Clicking, pain, headache, muscle tenderness, jaw deviation, movement restriction, limitation of mouth opening, as well as the presence of any radiographic changes). Calibration inter examiner reliability was done. Data were gathered and analyzed by statistical software: SPSS version 16.0 (SPSS Inc. Chicago, Illinois, USA). Informed consent was signed by study subjects prior to data collection after explanation of the procedure. Study was approved via Ethical committee of King Abdulaziz University Faculty of Dentistry (066$15)$.

\section{Results}

The mean age was 39years, with a male to female ratio 1:5. Results showed that $31 \%(n=25)$ of the study sample with pain, $45 \%$ $(\mathrm{n}=36)$ complained from headache, and clicking presented in 42.5 $\%(n=34)$. Upon examination of the muscles of mastication as well as Sternomastoid and Trapezius); $35 \%(\mathrm{n}=28)$ of study subjects had at least one tender muscle (Figure $1 \&$ Table 1). Subjects diagnosed with TMD constituted $72.5 \%(\mathrm{n}=58)$. Neither age nor gender had a significant effect on TMD. The $39.6 \%(\mathrm{n}=23)$ complaining from pain at the TMJ area among whom $6.8 \%(\mathrm{n}=4)$ reported that pain was sever and intolerable, however, $60 \%(\mathrm{n}=35)$ of the study subjects did not complain from pain. Prevalence of headache as a major symptom was $58.6 \%(n=34)$ of TMD patients. Clicking was found to be a symptom in $42 \%(\mathrm{n}=28)$ of patients with TMD. Muscle tenderness was recorded in $92.8 \%(n=26)$ of TMD patients (Figure 1).

Table I Frequencies of Ms Tenderness among study sample

\begin{tabular}{lllll}
\hline No. of tenders & Frequency & Percent & Valid percent & Cumulative percent \\
\hline 0 & 52 & 65 & 65 & 65 \\
\hline & 12 & 15 & 15 & 80 \\
2 & 7 & 8.8 & 8.8 & 88.8 \\
3 & 4 & 5 & 5 & 93.8 \\
4 & 3 & 3.8 & 3.8 & 97.5 \\
5 & 2 & 2.5 & 2.5 & 100 \\
Total & 80 & 100 & 100 & \\
\hline
\end{tabular}




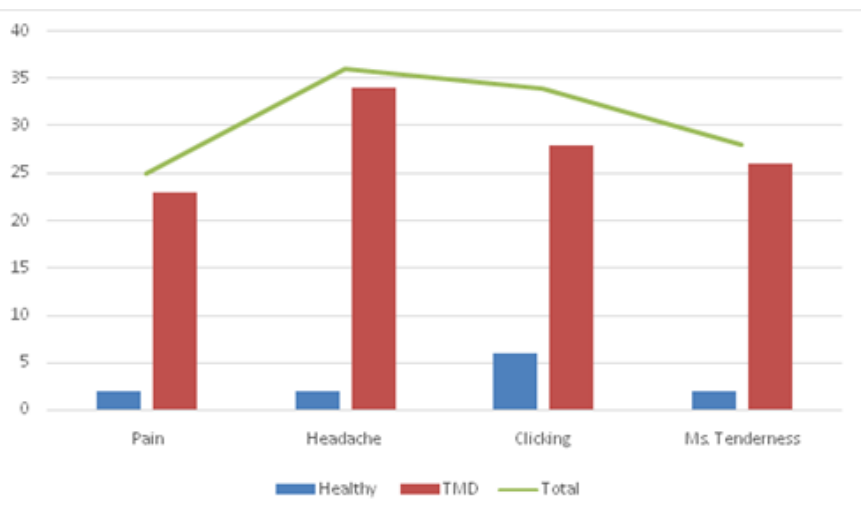

Figure I Pain, headache, clicking and Ms tenderness among study sample in relation to TMD.

\section{Patients who have one and more tenders}

Correlation of pain to TMD was performed to relate its frequency among the patients $28.7 \%(\mathrm{n}=23)$ suffering pain. Results showed a highly statistical significant difference regarding association between TMJ pain and TMD, since a higher proportion $(92 \%, 23$ out of 25$)$ of patients who had TMJ pain had TMD, whereas $(63.6 \%, 35$ out of 55) had no TMJ pain, but had TMD. The data provides evidence of statistical significant association between TMJ pain and TMD $(\mathrm{p}=0.008)$ (Table 2). Parafunctional habits such as: (lip biting, nail biting, bruxism and/or grinding) presented in $33.7 \%(n=27)$ of study subjects. However, $81.4 \%(\mathrm{n}=22)$ were associated with TMD (Figure

Table 2 Association between TMJ pain and TMD

\begin{tabular}{llllll} 
& Value & df & Asymp. sig.(2-sided) & Exact sig. (2-sided) & Exact sig. (I-sided) \\
\hline Pearson Chi-Square & $6.935 \mathrm{a}$ & $\mathrm{I}$ & 0.008 & & \\
Continuity Correctionb & 5.586 & $\mathrm{I}$ & 0.018 & & \\
Likelihood Ratio & 8.066 & $\mathrm{I}$ & 0.005 & 0.008 & 0.006 \\
Fisher's Exact Test & & & & & \\
Linear-by-Linear Association & 6.849 & $\mathrm{I}$ & 0.009 & \\
N of Valid Cases & 80 & & &
\end{tabular}

Table 3 Association between Bruxism and TMD

\begin{tabular}{llllll} 
& Value & df & Asymp. sig. (2-sided) & Exact sig. (2-sided) & Exact sig. (I-sided) \\
\hline Pearson Chi-Square & $3.372 \mathrm{a}$ & $\mathrm{I}$ & 0.066 & & \\
Continuity Correctionb & 2.013 & $\mathrm{I}$ & 0.156 & & \\
Likelihood Ratio & 5.475 & $\mathrm{I}$ & 0.19 & 0.099 & 0.066 \\
Fisher's Exact Test & & & & & \\
Linear-by-Linear Association & 3.33 & $\mathrm{I}$ & 0.068 & \\
N of Valid Cases & 80 & & &
\end{tabular}

Table 4 Association between Clenching and TMD

\begin{tabular}{llllll}
\hline & Value & df & Asymp. sig. (2-sided) & Exact sig. (2-sided) & Exact sig. (I-sided) \\
\hline Pearson Chi-Square & $1.020 \mathrm{a}$ & $\mathrm{I}$ & 0.312 & & \\
Continuity Correctionb & 0.526 & $\mathrm{I}$ & 0.468 & \\
Likelihood Ratio & $\mathrm{I} .074$ & $\mathrm{I}$ & 0.3 & $0.40 \mathrm{I}$ & 0.238 \\
Fisher's Exact Test & & & & & \\
Linear-by-Linear Association & $\mathrm{I} .008$ & $\mathrm{I}$ & 0.315 & \\
$\mathrm{~N}$ of Valid Cases & 80 & & &
\end{tabular}

Citation: Alhussini DA, Mominkhan DM,Alhamed FJ, et al. Prevalence and awareness of temporomandibular joint disorders among patients in king abdulaziz university, dental hospital. J Dent Health Oral Disord Ther. 20I7;8(5):603-608. DOI: I0.I5406/jdhodt.20I7.08.00300

2). There are no statistically significant association between Bruxism, Clenching and TMD $(p=0.099),(p=0.312)$ (Table $3 \& 4)$. Marked characteristics relevant to jaw movements were specifically related to TMD patients; $10 \%(\mathrm{n}=6)$ had a slight limitation of mouth opening $(<3.5 \mathrm{~cm})$, jaw deviation was recorded in $38 \%(\mathrm{n}=22)$, while $27.5 \%$ $(\mathrm{n}=16)$ had movement restriction with lateral movement, and $20.6 \%$ $(\mathrm{n}=12)$ with protrusive movement. Locking was found as well in $18.75 \%(n=15)$. Subjects free of signs and symptoms showed normal opening and jaw movement (Figure 3). Regarding occlusion; 68.7\% $(n=55)$ of the subjects were found to have unstable occlusion with multiple occlusal discrepancies as; overeruption, drifting, cross bite, high fillings, bad restorations and posterior teeth loss, $89 \%(n=49)$ of them experienced variable degrees of TMD signs and symptoms (Figure 4). There is statistically significant association between loss of posterior teeth and TMD. That is higher proportion $(82.5 \%, 33$ out of 40) patients who had loss of posterior teeth had TMD, whereas $(62.5 \%, 25$ out of 40$)$ had no loss of posterior teeth, but had TMD $(\mathrm{p}=0.045)$ (Table 5). Through radiographic assessment of condylar positioning within the glenoid fossa; $21 \%(n=17)$ showed unilateral anterior condylar position, and $21 \%(\mathrm{n}=17)$ bilateral anterior condylar positions; while, $17.5 \%(\mathrm{n}=14)$ had unilateral posterior condylar position, and $12.5 \%(\mathrm{n}=10)$ were found to have bilateral posterior condylar position (Figure 5). While comparing condylar location radiographically in open and closed positions, $18.75 \%(n=15)$ had a locked joint. Our results proved that $67.3 \%(n=39)$ suffering from TMD were unaware of their TMJ disorder, while $32.7 \%(n=19)$ knew that they have a TMJ related problem, that affected their quality of life as impairing function, affecting their mood and their daily performance (Figure 6). 
Table 5 Association between Loss of posterior teeth and TMD

\begin{tabular}{lllll}
\hline & Value & df & Asymp.sig. (2-sided) & Exact sig. (2-sided) \\
\hline Pearson Chi-Square & $4.013 \mathrm{a}$ & I & 0.045 \\
Continuity Correctionb & 3.072 & I & 0.08 \\
Likelihood Ratio & 4.084 & I & 0.043 \\
Fisher's Exact Test & & & \\
Linear-by-Linear Association & 3.962 & I & 0.047 & 0.078 \\
N of Valid Cases & 80 & &
\end{tabular}

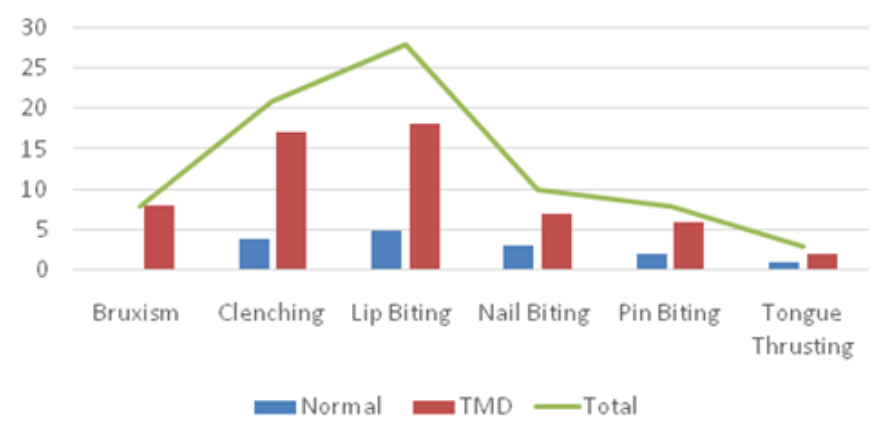

Figure 2 TMD in relation to parafunctional habits.

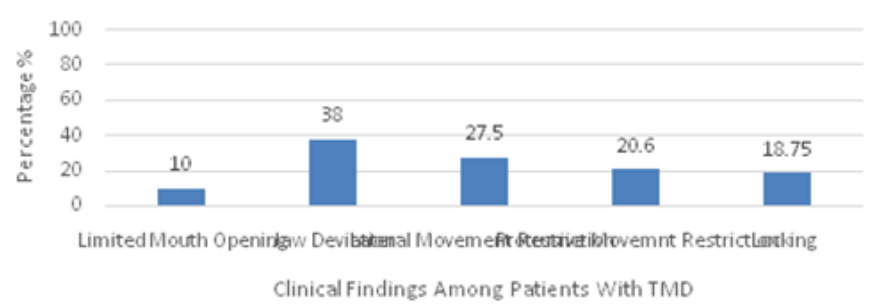

Figure 3 Clinical findings and marked characteristics showed in TMD subjects.

Cross Bite

\begin{tabular}{|c|c|c|c|c|c|c|}
\hline & $\begin{array}{l}0 \\
\text { Cross } \\
\text { Bite }\end{array}$ & $\begin{array}{l}10 \\
\text { Drifting }\end{array}$ & $\begin{array}{c}20 \\
\text { Over } \\
\text { Eruption }\end{array}$ & $\begin{array}{l}\text { Postêfior } \\
\text { Teeth } \\
\text { Loss }\end{array}$ & $\begin{array}{c}\text { Bad }^{0} \\
\text { Restorati } \\
\text { ons }\end{array}$ & $\begin{array}{l}\text { High } \\
\text { Fillings }\end{array}$ \\
\hline Free & 2 & 2 & 4 & 7 & 1 & 4 \\
\hline - TMD & 9 & 13 & 17 & 33 & 29 & 15 \\
\hline - Total & 11 & 15 & 21 & 40 & 30 & 19 \\
\hline
\end{tabular}

Figure 4 Occlusal discrepancies in relation to TMD.

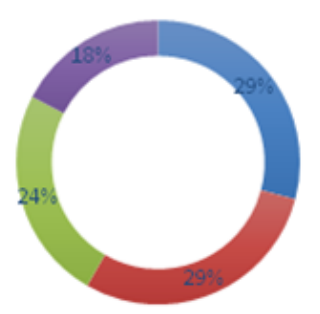

- unilateral anterior condylar position = Bilateral anterior condylar position = unilateral posterior condylar position = bilateral posterior condylar position

Figure 5 Condyar positioning within glenoid fossa.

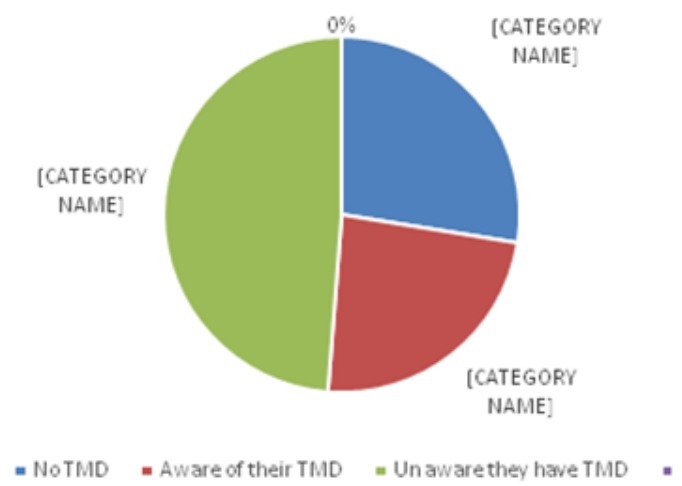

Figure 6 Patient's awareness in relation to TMD.

\section{Discussion}

The results of the present investigation at KAU-DH revealed that $72.5 \%$ of subjects experienced variable degrees of TMDs among whom $6.8 \%$ were reported as severe symptoms. This is comparable to an epidemiological study by Goncalves et al. ${ }^{15}$ involving a Brazilian population stating that TMD signs and symptoms existed in 30$39 \%$ of the sample. While Jang et al., ${ }^{16}$ reported a higher prevalence $(61.3 \%)$ within professional musicians and instrumentalists as well as high school students who attend music classes. ${ }^{15,16}$ Regarding age 
and TMD, our results like Goncalves et al. ${ }^{15}$ findings revealed a weak relation between age and TMD signs. However, Köhler et al., ${ }^{17}$ and Glass et al., ${ }^{18}$ noticed that TMD signs and symptoms increase with age, while in controversy, Jang et al... ${ }^{16}$, and found that TMD signs and symptoms are more common in young population. ${ }^{15-18}$ In our present work results showed no significant relation between gender and TMD despite higher awareness of females of their TMD problems, which agrees with Wang et al., ${ }^{19}$ and Goncalves et al. ${ }^{15}$ In contradiction; Jang et al. ${ }^{16}$ Andrea et al. ${ }^{20}$ found that TMD showed higher prevalence in female patients. ${ }^{19-21}$ Pain consisted a main symptom of our results where $39.6 \%$ of our sample complained from TMJ. This goes hand in hand with Jang et al., ${ }^{16}$ and Goncalves et al., ${ }^{15}$ advocations that TMJ pain is the second most common symptom within TMD patients. Moreover, Alkohtani et al., ${ }^{21}$ discovered that TMD pain was the most common complain within Saudi Arabian adolescents. ${ }^{16-23}$ $58.6 \%$ of our study subjects complained from headache as a major symptom. This could be attributed to the statement of the Headache Classification Committee of the International Headache Society (IHS) (2013), "that facial pain and headache are secondary to TMD, and intracranial structures do not originate pain or headache". This further agrees with Hara et al.. ${ }^{24}$, who found that headache and myofascial pain are strongly correlated to TMJ health status. ${ }^{24}$. Clicking was found to be a frequent symptom among KAU-DH patients (42\%) of patients with TMD. This conforms to a Canadian community study of TMD signs and symptoms by Locker D et al., ${ }^{25}$ who found that TMJ sounds were the most frequent presents as early articular changes. However, Glass et al., ${ }^{18}$ in a metropolitan area reported that only $10 \%$ of the population had joint sounds. ${ }^{18-25}$ Controversies regarding correlation of parafunctional habits to TMD were observed, since in our present work positive relation was recorded in accordance with previous results who was carried out by Fernandes et al., ${ }^{26}$ Wincour et al. ${ }^{27}$ Celic et al. Cortese et al., ${ }^{28}$ Fernandes et al. ${ }^{26}$ and Masoumeh et al. ${ }^{28}$ Moreover, in a cohort study by Akhter et al... ${ }^{29}$, about the effects of stress, trauma, and parafunctional habits on TMD symptoms over a 3-year period, stress and bruxism in female students and jaw injuries in male students were found to be associated with TMD. ${ }^{29}$ Additionally, Nomura et al., ${ }^{30}$ reported bruxism in $71.55 \%$ of dental students with varying levels of TMD. ${ }^{29}$ In controversy, established relation between bruxism, clenching and TMJ problems did not exist among Andrea et al. ${ }^{20}$ study sample. Furthermore, Barbosa et al. ${ }^{31}$ stated a controversial and unclear the relationship between bruxism and temporomandibular disorders. ${ }^{25-31}$ In the present study, limitation of jaw movements in the form of jaw deviation, restriction with lateral and protrusive movements and slight limitation upon mouth opening or even locking were recorded in relation to TMD, which agrees with similar results reported by Bianchini et al. ${ }^{32}$ Regarding occlusion; $68.7 \%$ of the subjects were found to have unstable occlusion with multiple occlusal discrepancies ranging from overeruption, drifting, cross bite, high fillings, bad restorations and posterior teeth loss, $89 \%$ of them experienced variable degrees of TMD signs and symptoms. Forty patients with loss of posterior teeth showed statistically significant association with TMD (82.5\%, 33 out of 40patients), while only $(62.5 \%, 25$ out of 40$)$ with no loss of posterior teeth exhibited TMD symptoms. This supports previous findings by Türp et al., ${ }^{33}$ who stated that loss of posterior support was considered one of the few dental factors with some consistency of evidence in the literature as causing TMD. ${ }^{33}$ Moreover, though Pullinger et al. ${ }^{34,35}$ reported that five or more missing posterior teeth led to a significant increase in risk for an individual to present TMD, especially osteoarthritis other authors suggested that its effect has been reported as very little or null on dysfunction incidence. ${ }^{5}$ Radiographs in our sample showed that among TMD patients; $42 \%$ of subjects had anterior condylar position, while; $30 \%$ had posterior condylar position. This agrees with Prabhu et al. ${ }^{36}$ who assessed condylar position in dentulous and edentulous subjects; and found more anterior condylar position among edentulous patients. This could be attributed to Uma et al..$^{37}$ advocations that myostatic contracture of lateral pterygoid within subjects who lost their posterior teeth, rebounded on condylar position. ${ }^{37}$ In the current study patients awareness of their condition was limited despite the fact that it is affecting their quality of life on daily basis. Similarly, Machado de Resende et al. ${ }^{38}$ conducted a study to assess the quality of life and general health in patients with temporomandibular disorders, concluded that patients with TMD require multiple focuses of attention since psychological indicators of general health and quality of life are likely associated with dysfunction. ${ }^{39}$

\section{Conclusion}

TMD is a multifactorial disease with different signs and symptoms that may affect the quality of life of the patients. In our local population the disease proved to exist manifesting itself by two or more of the symptoms that negatively affect the patients' quality of life. Moreover, awareness of the patients of their conditions was not clearly understood which requires better community orientation about the significance of the disease to avoid its progresses if left unnoticed.

\section{Acknowledgments}

The authors would like to thank their colleagues for their generous insight and expertise that greatly assisted the research.

\section{Conflicts of interest}

The authors declare that they have no conflict of interest.

\section{Funding}

None.

\section{References}

1. Gupta S, Gupta R. Partial edentulism and Temporomandibular joint disorders. Journal of Dental and Medical Sciences. 2014;13(12):60-63.

2. Granados JI. The influence of the loss of teeth and attrition on the articular eminence. J Prosthet Dent. 1979;42(1):78-85.

3. Romero-Reyes M, Uyanik JM. Orofacial pain management : current perspectives. J Pain Res. 2014;7:99-115.

4. Alzarea BK. Temporomandibular Disorders (TMD) in Edentulous Patients: A Review and Proposed Classification (Dr. Bader's Classification). J Clin Diagnostic Res. 2015;9(4):ZE06-ZE09.

5. Sipilä K, Näpänkangas R, Könönen $M$, et al. The role of dental loss and denture status on clinical signs of temporomandibular disorders. J Oral Rehabil. 2013;40(1):15-23.

6. Tallents RH, Macher DJ, Kyrkanides S, et al. Prevalence of missing posterior teeth and intraarticular temporomandibular disorders. J Prosthet Dent. 2003;87(1):45-50.

7. Magnusson C, Nilsson M, Magnusson T. Degenerative changes in human temporomandibular joints in relation to occlusal support. Acta Odontol Scand. 2010;68(5):305-311.

8. Sarita PTN, Kreulen CM, Witter D, et al. Signs and symptoms associated with TMD in adults with shortened dental arches. Int J Prosthodont. 2003;16(3):265-270. 
9. Greene CS. The etiology of temporomandibular disorders: implications for treatment. J Orofac Pain. 2001;15(2):93-116.

10. Craddock HL. Occlusal Changes Following Posterior Tooth Loss in Adults. Part 3. A Study of Clinical Parameters Associated with the Presence of Occlusal Interferences Following Posterior Tooth Loss. $J$ Prosthodont. 2007;16(6):485-494.

11. Roda RP, Bagán JV, María J, et al. Review of temporomandibular joint pathology . Part I : Classification, epidemiology and risk factors. Med Oral Patol Oral Cir Bucal. 2007;12(4):E292-E298.

12. Zakrzewska JM. Differential diagnosis of facial pain and guidelines for management. Br J Anaesth. 2013;111(1):95-104.

13. Muhamed Ajanovic, Benjamin Bejtovic. Correlation Between Values of the Helkimo Anamnestic and Clinical Dysfunction Index in Patients Suffering from Post Traumatic Stress Disorder. Mater Socio Medica. 2009;21(2):85-91.

14. Sena MF, Mesquita KS, Santos FR, et al. Prevalence of temporomandibular dysfunction in children and adolescents. Rev Paul Pediatr. 2013;31(4):538-545.

15. Gonçalves DA de G, Dal Fabbro AL, Campos JADB, et al. Symptoms of temporomandibular disorders in the population: an epidemiological study. J Orofac Pain. 2010;24(3):270-278.

16. Jang JY, Kwon JS, Lee DH, et al. Clinical Signs and Subjective Symptoms of Temporomandibular Disorders in Instrumentalists. Yonsei Med J. Yonsei University College of Medicine. 2017;57(6):1500-1507.

17. Köhler AA, Helkimo AN, Magnusson T, et al. Prevalence of symptoms and signs indicative of temporomandibular disorders in children and adolescents. A cross-sectional epidemiological investigation covering two decades. 2009;10(Suppl 1):16-25.

18. Glass EG, McGlynn FD, Glaros AG, et al. Prevalence of temporomandibular disorder symptoms in a major metropolitan area. Cranio. 2017;11(3):217-220.

19. Wang MQ, Xue F, He JJ, et al. Missing posterior teeth and risk of temporomandibular disorders. J Dent Res. 2009;88(10):942-945.

20. Andrea M Chisnoiu, Buduru S, Lascu L, et al. Influence of occlusal characteristics on temporomandibular joint disorder development -a cross-sectional study. Human \& Veterinary Medicine. International Journal of the Bioflux Society. 2013;7(3):197-201.

21. Al-Khotani A, Naimi-Akbar A, Albadawi E, et al. Prevalence of diagnosed temporomandibular disorders among Saudi Arabian children and adolescents. J Headache Pain. 2016;17:41.

22. Abarca M, Van Steenberghe D, Malevez C, et al. The neurophysiology of osseointegrated oral implants. A clinically underestimated aspect. J Oral Rehabil. 2006;33(3):161-169.

23. Widmalm SE, Westesson PL, Kim IK, et al. Temporomandibular joint pathosis related to sex, age, and dentition in autopsy material. Oral Surg Oral Med Oral Pathol. 1994;78(4):416-425.

24. Hara K, Shinozaki T, Okada-Ogawa A, et al. Headache attributed to temporomandibular disorders and masticatory myofascial pain. J Oral Sci. 2016;58(2):195-204.
25. Locker D, Slade G. Prevalence of symptoms associated with temporomandibular disorders in a Canadian population. Community Dent Oral Epidemiol. 1988;16(5):310-313.

26. Fernandes G, Franco-Micheloni AL, Siqueira JTT, et al. Parafunctional habits are associated cumulatively to painful temporomandibular disorders in adolescents. Braz Oral Res. 2016;30.

27. Winocur E, Littner D, Adams I, et al. Oral habits and their association with signs and symptoms of temporomandibular disorders in adolescents: a gender comparison. Oral Surg Oral Med Oral Pathol Oral Radiol Endod. 2006;102(4):482-487.

28. Cortese SG, Biondi AM. Relationship between dysfunctions and parafunctional oral habits, and temporomandibular disorders in children and teenagers. Arch Argent Pediatr. 2009;107(2):134-138.

29. Akhter R, Morita M, Esaki M, et al. Development of temporomandibular disorder symptoms: a 3-year cohort study of university students. J Oral Rehabil. 2011;38(6):395-403.

30. Nomura K, Vitti M, Oliveira AS de, et al. Use of the Fonseca's questionnaire to assess the prevalence and severity of temporomandibular disorders in Brazilian dental undergraduates. Braz Dent J. 2007;18(2):163-167.

31. Barbosa T de S, Miyakoda LS, Pocztaruk R de L, et al. Temporomandibular disorders and bruxism in childhood and adolescence: Review of the literature. Int J Pediatr Otorhinolaryngol. 2008;72(3):299-314.

32. Bianchini EMG, Paiva G, Andrade CRF de. Mandibular Movement Patterns During Speech in Subjects with Temporomandibular Disorders and in Asymptomatic Individuals. Cranio. 2008;26(1):50-58.

33. Türp JC, Schindler H. The dental occlusion as a suspected cause for TMDs: epidemiological and etiological considerations. J Oral Rehabil. 2017;39(7):502-512.

34. Pullinger AG, Seligman DA, Gornbein JA. A multiple logistic regression analysis of the risk and relative odds of temporomandibular disorders as a function of common occlusal features. J Dent Res. 1993;72(6):968-979.

35. Pullinger AG, Seligman DA. Quantification and validation of predictive values of occlusal variables in temporomandibular disorders using a multifactorial analysis. J Prosthet Dent. 2000;83(1):66-75.

36. De Sousa ST, De Mello VVC, Magalhães BG, et al. The role of occlusal factors on the occurrence of temporomandibular disorders. Cranio. 2015;33(3):211-216.

37. Uma MP, Rajesh S, Kamalakanth KS. Cephalometric evaluation of condyle-fossa position in dentulous and edentulous subjects. Indian $J$ Dent Res. 2015;26(3):256-261.

38. Camila Maria Bastos Machado de Resende, Arthur César de Medeiros Alves, Lidiane Thomaz Coelho, et al. Quality of life and general health in patients with temporomandibular disorders. Braz Oral Res. 2013;27(2):116-121.

39. Jerjes W, Upile T, Abbas S, et al. Muscle disorders and dentition-related aspects in temporomandibular disorders: controversies in the most commonly used treatment modalities. Int Arch Med. 2008;1(1):23. 